\title{
Amyloidosis complicating psoriasis
}

*B. AMIR-ANSARI
M.D.

\author{
A. M. JoEKeS \\ M.A., B.M., B.Ch., F.R.C.P.
}

\author{
M. C. PARKINSON \\ M.D., M.R.C.Path.
}

The Institute of Urology, St Peter's Hospital, London, W.C.2; Department of Nephrology, St Philip's Hospital, Sheffield Street, London, W.C.2; and Department of Histopathology, St Paul's Hospital, 24 Endell Street, London, W.C.2.

\section{Summary}

A man aged 59 years with a 39-year history of psoriasis, for which treatment had included steroids and methotrexate, developed renal failure caused by amyloidosis. Post-mortem revealed widespread amyloid deposits but no evidence of other disease classically associated with amyloidosis.

\section{Introduction}

In major reviews of amyloidosis (Glenner, Terry and Isersky, 1973; Stirling, 1975) psoriasis is not listed as one of the predisposing causes nor is it mentioned as an aetiological factor in renal amyloidosis (Heptinstall, 1974). Case reports have drawn attention to amyloidosis in patients with pustular psoriasis (Berger, 1969; Mackie and Burton, 1974) and psoriatic arthritis (Reed and Wright, 1966; Ferguson and Wilson Downie, 1968; Brownstein and Helwig, 1970; Lambert et al., 1973; Qureshi et al., 1977). In this paper a patient with erythrodermic psoriasis and fatal amyloidosis is described.

\section{Case report}

A 59-year-old man was referred for investigation of proteinuria. He had suffered for 39 years from psoriasis which had necessitated multiple hospital admissions. He had been treated with occlusive dressings, courses of hydroxyurea, oral and topical steroids and methotrexate. As a sequel to the latter therapy liver biopsies obtained on four separate occasions were examined, the last one 3 years before his death; no significant abnormality was reported in any of these specimens. During the previous two years he had received treatment for chronic bronchitis.

\footnotetext{
*Request for reprints to Dr B. Amir-Ansari, M.D., Department of Nephrology, St Philip's Hospital, Sheffield Street, London, W.C.2.
}

On admission the patient had generalized eryth- ${ }_{-\infty}^{\infty}$ ema with exfoliation and subtotal alopecia; naip dystrophy was evident but there was no arthropathy응 He was dyspnoeic on exertion with widespread respiratory wheeze. The blood pressure was $130 / 70$ $\mathrm{mmHg}$ lying and $140 / 80 \mathrm{mmHg}$ standing. The liver was palpable with a smooth edge and was not tender. No other abnormality was revealed 85 physical examination.

On investigation urine volumes varied betwen 1000 and $1500 \mathrm{ml} / 24 \mathrm{hr}$ with proteinuria of $3-55$ $\mathrm{g} /$ day. The glomerular filtration rate was $32 \mathrm{ml} / \mathrm{min}$ and effective renal plasma flow $130 \mathrm{ml} / \mathrm{min}$ (Con® stable et al., 1979). Total plasma proteins were 59 $\mathrm{g} / \mathrm{l}$ with an albumin level of $23 \mathrm{~g} / \mathrm{l}$. The plasma $\operatorname{IgA}$ was 455 i.u./ml (normal range $53-309$ i.u. $/ \mathrm{ml}$ ), levels of both IgG and IgM were normal and the electrophoretic strip showed no evidence of a paraproteino? The plasma alkaline phosphatase was $156 \mathrm{u} . \bar{f}$ (normal 28-92 u./l), hepato-cellular enzymes and bilirubin were normal. The latex test was positive a's a titre of 1 in 320 but the sheep red cell agglutination. test for rheumatoid factor (RF) was positive onlyo at a titre of 1 in 2 with sensitized cells and negative with unsensitized cells. Culture of sputum grews Pseudomonas aeruginosa.

In the renal biopsy there were widespread amylois. deposits involving the glomeruli, interstitial tissue interlobular arteries and afferent arterioles (Fig. 1)? Biopsy materials studied with anti-AA and anti-APO antibodies showed that the amyloid deposits werê of secondary type.

Despite supportive treatment the patient's renab function deteriorated, he suffered recurrent chest in fections and died having developed profuse diar $\stackrel{0}{?}$ rhoea in the terminal five days. Post-mortem ando post-mortem histology revealed widespread amyloid deposits in the gastrointestinal tract, liver, pancreas 


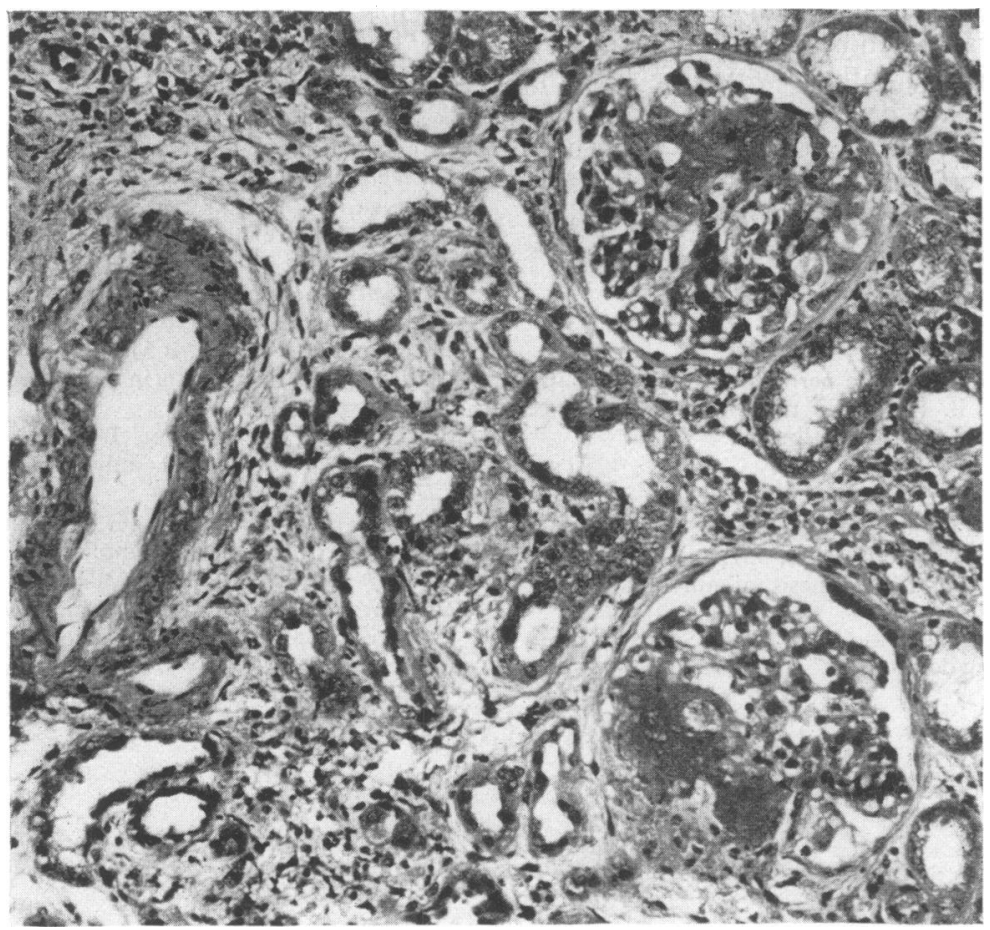

FIG. 1. Renal biopsy showing amorphous deposits in 2 glomeruli and an interlobular artery (HE, $\times 200)$. Amyloid was confirmed by Sirius red stain and showed birefringence with polarized light.

adrenal glands, thyroid, lymph nodes, spleen and testes in addition to the kidneys. Amyloid was not seen in either myocardium or lungs. Throughout the small intestine foci of ischaemic mucosal ulceration were associated with amyloid deposits in the mural arteries; the superior mesenteric vessels were patent. Features of chronic bronchitis were present in the lungs and bronchopneumonia with scarring was seen in the lower lobes. No evidence of myelomatosis was seen in the bone marrow.

In view of these findings 2 of the liver biopsies taken 8 and 3 years before death were reviewed; in the latter specimen amyloid was identified by the Sirius red stain in the walls of 2 small arteries.

\section{Discussion}

Amyloid is classically divided into primary and secondary types; the former is idiopathic or associated with multiple myeloma and the latter follows a variety of conditions commonly of a chronic inflammatory or malignant nature. These two forms of amyloid differ in chemical composition (Leading Article, 1979). In this case there was no clinical or laboratory evidence of multiple myelomatosis; chest infections were a recent complication and amyloid was subsequently identified in a liver biopsy before their onset. The patient did not have an arthropathy and although the positive latex test is unexplained the results of the sheep cell agglutination test for RF would make a diagnosis of early rheumatoid arthritis extremely unlikely. As necropsy failed to reveal any occult inflammatory or malignant condition an association between psoriasis and amyloidosis was considered.

Amyloidosis has only rarely been diagnosed in association with psoriasis usually as the result of renal involvement (Reed and Wright, 1966; Brownstein and Helwig, 1970; Mackie and Burton, 1974), gastrointestinal tract symptoms (Ferguson and Wilson Downie, 1968; Qureshi et al., 1977) or abnormalities in both these systems (Berger, 1969). In these cases there was commonly a long history of severe psoriasis in the pustular form often complicated by psoriatic arthropathy. The patient described in this paper had a long history of psoriasis but of the erythrodermic type and he did not have an arthropathy. His death was caused by renal amyloidosis and vascular amyloid deposits were considered a contributory factor in the terminal intestinal ischaemia. An immunofluorescence study with anti-AA and anti-AP antibodies confirms that the amyloid was of secondary, i.e. AA type. 
The patient described in this paper and other cases in the literature indicate that amyloidosis should be considered in patients with long-standing severe psoriasis who develop renal or gastrointestinal tract symptoms. Furthermore, when liver biopsy has been performed to assess methotrexate toxicity in psoriatics special stains for amyloid should be examined or an opportunity to diagnose amyloidosis may be missed.

\section{Acknowledgments}

Professor M. W. Greaves gave permission for this case to be published. Dr M. B. Pepys did the immunofluoresence studies for anti-AA and anti-AP antibodies.

\section{References}

Berger, P.A. (1969) Amyloidosis: a complication of pustular psoriasis. British Medical Journal, 2, 351.

Leading Article (1979) Pathogenesis of amyloid disease. British Medical Journal, 1, 216.

Brownstein, M.H. \& Helwig, E.B. (1970) Systemic amyloidosis complicating dermatoses. Archives of Dermatology, 102, 1 .
Constable, A.R., Hussein, M.M., Albrecht, M.P., Thompson, F.D., Philalithis, P.E. \& Joekes, A.M. (1979) Single sample estimates of renal clearances. British Journal of Urology, 51, 84.

FERGUSON, A. \& WILSON DownIE, W. (1968) Gastrointestinal amyloidosis in psoriatic arthritis. Annals of the Rheumatic Diseases, 27, 245.

Glenner, G.G., Terry, W. \& Isersky, C. (1973) Amyloidosis: Its nature and pathogenesis. Seminars in Hematology, 10,65 .

Heptinstall, R.H. (1974) Pathology of the Kidney, Vol. 2, तึ p. 737. Little, Brown and Company, Boston.

LAMbert, J.R., ANSEll, B.M., Stephenson, E. \& Wright, V. ڤ (1973) Psoriatic arthritis in childhood. Clinics in Rheumatic $\overrightarrow{0}$ Diseases, 2, 339.

Mackie, R.M. \& Burton, J. (1974) Pustular psoriasis in $\vec{\omega}$ association with renal amyloidosis. British Journal of $\underset{\mathcal{W}}{ }$ Dermatology, 90, 567.

Qureshi, M.S.A., SANdle, G.I., Kelly, J.K. \& Fox, H. (1977) Amyloidosis complicating psoriatic arthritis. British Medical Journal, 2, 302.

REED, W. \& WRIGHT, V. (1966) Modern Trends in Rheumatology, p. 382. Butterworths, London.

Stirling, G.A. (1975) Recent Advances in Pathology, p. 249. Churchill Livingstone, London. 